\title{
Venezuela: o Papel dos Processos de Integração para a Manutenção do Governo Chávez
}

\author{
Rodrigo Herrero Lopes \\ Verena Hitner ${ }^{(*)}$
}

Resumo: O artigo pretende analisar a atuação da Venezuela dentro dos processos de integração existentes atualmente na América Latina, procurando verificar como a política externa possui papel fundamental na política interna venezuelana, mais especificamente na consolidação do projeto "bolivariano" e na consequente manutenção do grupo chavista no poder.

Palavras-chave: América Latina, Integração Regional, Venezuela, Política Externa.

\begin{abstract}
This article aims to analyze Venezuela's work in the contemporary Latin-American integration processes. It intend to verify how important is Venezuelan external politics for its internal politics, especially for the consolidation of "bolivarian" project and for the consequent staying of Chávez' group on the power.
\end{abstract}

Keywords: Latin America, Regional Integration, Venezuela, External Policy.

(*) Verena Hitner: Cientista social e mestranda pelo PROLAM/USP. E-mail: <hit003@terra.com.br>. Rodrigo Herrero Lopes: Jornalista e mestrando pelo PROLAM/USP. E-mail:<rodrigo.herrero@gmail.com>. Recebido em 22.9.09 e aceito em 25.10.09. 


\section{INTRODUÇÃO}

O artigo trata das recentes mudanças na política externa venezuelana e de suas repercussões no processo integracionista sul-americano. A tese central do texto é a de que a estratégia inicial do governo Chávez, como mostra seu programa de governo e principalmente o Plano de Desenvolvimento da Nação (2001-2007), é a de voltar-se para a América do Sul, formando, assim, um movimento contra-hegemônico único, que pudesse fazer frente à Área de Livre-Comércio das Américas (Alca). Isso porque a política externa é fundamental para garantia da legitimidade e consequente permanência no poder do grupo chavista.

Para tanto, o texto parte de um breve histórico da política externa da Venezuela desde a "Doutrina Betancourt", da década de 50, que influenciou todo o período em que vigorou o pacto de Punto Fijo (1958-1998), para contrapô-la à política exterior "bolivariana" de Hugo Chávez. Nesta análise é ressaltado o papel do petróleo como instrumento de poder e discutidas as idas e vindas do esforço integracionista da terceira economia do subcontinente. Essa discussão é importante, uma vez que tenta demonstrar a razão pela qual a Venezuela sempre esteve voltada para fora do nosso subcontinente. A "Doutrina Betancourt" foi propulsora de um isolamento regional que levou, entre outros aspectos, ao retardamento da adesão do país à Área de Livre-Comércio Latino-Americano (Alalc), contrariando o movimento de integração sul-americana. A aproximação aos Estados Unidos e a dependência do petróleo foram as outras principais consequências desta política.

Nos anos noventa, a política externa começa a ser redirecionada ainda nos governos de Carlos Andrés Pérez e Rafael Caldera. Porém, somente quando Hugo Chávez assume a presidência do país, formulando não somente uma nova constituição, como também uma nova política externa, pode-se dizer que a "Doutrina Betancourt" deixou de existir. Essa nova política externa não pode ser entendida de maneira isolada, uma vez que faz parte do processo de mudança institucional, vivido na Venezuela dos últimos anos, que começa com a constituinte, aprimora suas formas no Plano de Desenvolvimento da Nação 2001-2007 e se explicita na tentativa de entrada no Mercosul. Isso será discutido na segunda parte do artigo, quando trataremos a ideia de que essa mudança da política externa só foi possível devido à conjuntura internacional extremamente favorável: alta dos preços internacionais do petróleo, eleição de governos sem alinhamento automático aos Estados Unidos na América Latina e mudança na ordem de prioridades da política externa norte-americana, que tirou a Alca do topo da lista.

Se num primeiro momento as preocupações externas do governo chavista foram dirigidas à rearticulação da Organização dos Países Produtores de Petróleo (Opep), a partir de 2001 é nítida a prioridade à integração sul-americana, incluindo uma mudança na forma de integração. A compra de títulos da dívida argentina, manifestações explícitas de apoio às candidaturas presidenciais nas eleições bolivianas, equatorianas e peruanas e a proposta da Alternativa Bolivariana para as Américas (Alba) fazem parte deste movimento, que é fundamental para a permanência de Chávez no poder.

Desse modo, na terceira parte do artigo, trataremos de forma panorâmica da participação venezuelana nos processos integracionistas atuais, como prelúdio para, nas partes 
seguintes, realizar um estudo mais aprofundado de dois processos de integração nos quais a Venezuela está inserida atualmente na região: em primeiro lugar, discutiremos a importância do Mercado Comum do Sul (Mercosul) para a Venezuela e sua tentativa de fazer parte do bloco como membro permanente. Em seguida, apresentaremos a Alba e alguns acordos realizados dentro de seus parâmetros. Vale ressaltar que optamos por discutir esses dois processos, pois avaliamos serem os mais importantes na atualidade venezuelana.

\section{ANTECEDENTES: DEMOCRACIA REPRESENTATIVA E PETRÓleo}

Desde o governo de Rômulo Betancourt, na década de cinquenta, a Venezuela vive de costas para a América Latina, opondo-se aos projetos de integração sub-regional. Isso porque seus interesses econômicos condicionavam, de duas formas, a política exterior: de um lado estava incumbida de lutar pela manutenção da quota do petróleo no mercado norte-americano e, de outro, defender o protecionismo e as restrições às importações em nome da necessária industrialização interna. O governo Betancourt é o primeiro depois da democratização do país. De acordo com Romero (2002), esta é a primeira vez que se pode falar de uma política externa venezuelana, com ações coerentes e estruturadas, pensadas a partir de um projeto nacional.

A "Doutrina Betancourt" foi uma estratégia do governo que enfatizou sua ação exterior na Organização dos Estados Americanos (OEA) e priorizou, por causa do petróleo, as relações econômicas bilaterais com os Estados Unidos. Cervo (2001) indica as principais diretrizes de política externa da Venezuela e sua ação na região durante esse período: "a dependência das exportações de petróleo, cerca de 90\% do total; a dependência dos Estados Unidos, principal investidor, cliente e fornecedor, e a repercussão interna dos acontecimentos políticos na área do Caribe" (CERVO, 2001, p. 159).

A Doutrina fixou diretriz política rígida no trato dos vizinhos, ao decidir somente reconhecer governos oriundos de eleições realizadas sob normas constitucionais. Dessa forma, os discursos venezuelanos na OEA eram sempre de repúdio a governos não democráticos - propondo sanções contra o regime de Fidel Castro, em Cuba, e de Rafael Leônidas Trujillo, na República Dominicana - e de fortalecimento do sistema interamericano, dando personalidade jurídica à "Doutrina Betancourt". Essa Doutrina, somada ao fato de a Venezuela ter optado por relações econômicas quase exclusivas com os Estados Unidos, a levou ao distanciamento em relação aos demais países da América Latina.

No início dos anos sessenta, a Venezuela criou, com países árabes e africanos, a Opep, com a finalidade de defender o preço do petróleo e garantir superávits na balança comercial. Ao mesmo tempo, mantinha-se fora do Acordo Geral de Tarifas e Comércio (GATT na sigla em inglês) e da Alalc, preferindo acordos bilaterais. Na origem dessa política externa estava o receio de que o liberalismo comprometesse seu projeto nacional de industrialização e a evidência de que a Venezuela era um país fundamentalmente petroleiro. A oposição venezuelana à Alalc e ao acordo de integração sub-regional dos países andinos fechava o cerco aos negócios sul-americanos. 
Ainda nesse momento, a Venezuela inicia um período de quarenta anos de estabilidade, denominado Punto Fijo (1958-1998).

A base material do Pacto Punto Fijo foi dada pela distribuição clientelista da renda petrolífera. A existência do petróleo condicionou a forma de intervenção do Estado na economia, e também a relação deste com o restante dos atores políticos, tais como partidos, sindicatos, forças armadas e setor privado (VILLA, 2005, p. 154).

Durante esse período vários setores se apropriam da renda petroleira; todos ganharam, embora uns tivessem ganhado mais do que outros; foi assim até o fim da década de setenta. A década de setenta deu à Venezuela novas condições de projetar seu prestígio em razão da alta dos preços do petróleo. Em relação à política externa do período, a partir da eleição de Rafael Caldera Rodríguez, em 1968, a "Doutrina Betancourt" não passaria a ser mais aplicada com tanto afinco, dando prioridade à criação de laços com países que poderiam consumir o petróleo produzido pela Venezuela.

Em 1976, ao final do governo Pérez, a Venezuela nacionalizou a indústria petroleira. Acreditava-se que a estatal Petróleos de Venezuela (Pdvsa) seria a casa matriz de um conjunto de empresas que até a noite anterior eram transnacionais. Desse modo, o que mudou na política externa venezuelana é que, se antes da nacionalização o Estado taxava as companhias de petróleo e buscava, com isso, o aumento dos preços no mercado internacional, com a nacionalização, e consequente criação da Pdvsa, o petróleo passa a ser controlado pela burocracia da empresa, que é venezuelana, mas que advém das oligarquias petroleiras anteriores, e que, portanto, se configura como um grupo social internacionalizado (MOMMER, 2003). O sucesso do petróleo, causado pelos seus preços exorbitantes nessa época, indicou um retorno ao pensamento bolivariano de liderar a América Latina, integrando-a em torno da Venezuela.

A partir dos anos oitenta e até o final dos anos noventa, os preços internacionais do petróleo caem, com algumas variações, de maneira constante. Internamente, os recursos petroleiros que chegavam a todas as classes tornam-se, cada vez mais, restritos aos grupos sociais ligados ao Estado e à companhia de petróleo. O período da Apertura Petrolera, a partir de 1990, reduziu, de forma significativa, a arrecadação de impostos e preparou o terreno para a desnacionalização da Pdvsa. Entre outras coisas, ela liberou a entrada de capitais transnacionais nas atividades primárias, reduziu a soberania jurídica e impositiva, diminuiu de forma significativa os ingressos fiscais do petróleo e colocou a Venezuela em rota de colisão com os outros sócios da Opep.

Na política externa, o modelo neoliberal significava a defesa de uma nova proposta de "regionalismo aberto" (CEPAL, 1998), ou seja, a integração passa a ser vista, então, como um mecanismo relevante, mas com um papel diferenciado, já que o objetivo não é mais substituir em escala regional as importações, mas permitir ao país uma inserção no cenário internacional. A política exterior foi, portanto, reorientada do norte e oeste para o sul e leste. O país deixava seu isolamento para trás, mesmo porque essa política não seria coerente com a desregulamentação e liberalização dos mercados latino-americanos. 
A Venezuela passa a guiar sua política externa por "uma orientação realista, que articulava os objetivos da cooperação e da integração com o esforço interno de desenvolvimento" (CERVO, 2001, p. 161), devido graças à reorientação dos dois partidos que davam as cartas no país àquela época. Essa mudança de visão foi aproveitada pelo Brasil que fez diversos acordos com a Venezuela e a Argentina, principalmente nas áreas energética e comercial. "A mudança política regional da Venezuela representou, portanto, injeção de ânimo tanto para os movimentos de integração quanto para a cooperação bilateral entre vizinhos" (CERVO, 2001, p. 161).

Segundo Villa (2005), o primeiro ato que revela a ausência de estabilidade política do sistema democrático venezuelano e que foi primordial para arrebentar com as instituições democráticas do Pacto de Punto Fijo foi o Caracaço $^{(1)}$, provocando a morte de trezentas pessoas, segundo dados oficiais. Fontes extraoficiais estendem o número para mais de mil mortos. Pode-se dizer que esta manifestação preparou o terreno para o que se seguiria. Em 1992 houve uma tentativa malograda de golpe, liderada pelo então tenente-coronel Hugo Chávez Frias, agravando a crise política. No ano seguinte, Carlos Andrés Pérez foi afastado do governo, acusado de corrupção. Tentou-se um arremedo de reforma para tentar manter as instituições democrático-burguesas, sem o sucesso esperado para manter o sistema sem deformações.

O enfraquecimento do pacto entre elites provocou um vazio na política do país, que acabou sendo preenchido de forma eloquente por Chávez.

O radicalismo do discurso chavista, que precede as eleições presidenciais de 1998, transformou-o naquele que melhor interpretava o desejo de mudança popular, tanto em relação à classe política dominante como em relação às suas instituições legadas pela Constituição de 1961 (VILLA, 2005, p. 159).

E sua vitória, com mais de 58\% dos votos válidos em dezembro de 1998, trouxe mudanças importantes tanto para a política da Venezuela como para a da própria América Latina. O discurso bolivariano volta para ficar, transformando-se num elemento concreto de ação política, seja na arrumação da casa, seja no sentido de integrar e formar uma grande nação latino-americana.

\section{A política bolivariana de INTEGRAÇÃo}

Não há como entender a política externa venezuelana após a chegada de Hugo Chávez ao poder sem entender a dinâmica interna do país e a relação que esta tem com o petróleo. Ainda na campanha presidencial de 1998, a candidatura de Hugo Chávez aglutinou amplos setores críticos à política de Apertura Petrolera. Após o triunfo eleitoral de Chávez, a Apertura começou a ser freada com a aprovação da Constituição Bolivariana, que prevê, expressamente em seu artigo 303, a proibição da privatização da Pdvsa. No

(1) No dia 27 de fevereiro de 1989, uma manifestação popular contra as medidas do governo — mais especificamente contra a alta do transporte coletivo por conta do aumento no preço dos combustíveis - teve em seu ponto central a capital Caracas; daí o nome do evento, espalhando-se por toda a Venezuela, sendo, porém, reprimido pelos militares. 
início de seu governo, Hugo Chávez buscou rearticular a Opep: realizou viagens para a Líbia, Argélia, Irã e Iraque. Em 2000 foi realizada a segunda reunião de chefes de Estado da história do cartel, em Caracas. O êxito dessa empreitada foi inquestionável: antes mesmo dos ataques de 11 de setembro de 2001 e da segunda ocupação do Iraque, o preço do petróleo já havia subido de US\$ 9 para quase US\$ 20 o barril.

A partir da promulgação das 49 Leis Habilitantes, em novembro de 2001, inicia-se o primeiro enfrentamento direto do governo Chávez com os setores majoritários da gerência da Pdvsa. A Lei de Hidrocarbonetos fez parte deste pacote de 49 leis decretadas pelo presidente Chávez, e previa um aumento nos repasses ao Estado para novas licenças e que a contabilidade das atividades internas e externas da companhia deveria ser feita em separado, o que explicitaria que as atividades internas geravam muitos excedentes, enquanto que as externas, enormes prejuízos. Este mecanismo garantia a apropriação dos recursos do petróleo por uma casta da burocracia da Pdvsa.

Esse ato marcou o início da rearticulação dos setores antichavistas derrotados na eleição de 1998 e na Constituinte de 1999. Neste momento o governo passa a ser acusado fortemente pela grande mídia, pelo sindicato patronal Fedecámaras e por setores conservadores de dividir o país, de atentar contra a propriedade privada e de querer implementar um regime castrista na Venezuela. Todavia, a Pdvsa seguiu sua política autônoma de gestão e de internacionalização, que só foi revertida em fevereiro de 2003, quando, depois de mais de dois meses de greve da companhia, conhecida como Paro Petrolero, com o objetivo de derrubar Hugo Chávez da Presidência da República, o governo interveio, demitindo 17 mil funcionários, inclusive a maioria da direção da Companhia (BARROS, 2007 , p. 129). Essas vitórias chavistas alijam do poder os partidos conservadores que até então mandavam no jogo político, inaugurando o que Amado Cervo (2001) chama de "nacionalismo social", diferente, portanto, do já tradicional conservadorismo e da experiência neoliberal que eclodiu a crise venezuelana.

Com isso, foi possível Chávez voltar-se para fora do país e, mais ainda, do subcontinente, indo muito além da rearticulação da Opep. A Venezuela chavista tem firmado acordos por todo o mundo, abrindo horizontes impensados até então para o país, como Argélia, Nigéria, China e Rússia, expandindo a exportação de petróleo para os chineses e comprando armamentos russos em grande quantidade. Criou a Alba com Cuba, como veremos a seguir, a partir do fornecimento de petróleo a condições extremamente favoráveis, juros baixos e prazo extenso para pagamento, em troca de médicos e metodologia de ensino do país de Fidel Castro. Isto mostra como, além de uma atuação maior no plano mundial, a política externa do país é enfatizada nos vizinhos, segundo palavras do Ministro de Relações Exteriores da Venezuela, José Vicente Rangel, tendo quatro áreas básicas para o esforço de sua diplomacia: a atlântica, a caribenha, a andina e a amazônica. Ao qual Cervo complementa:

Seus objetivos desdobrar-se-iam na implementação de importantes projetos de cooperação bilateral e na determinação de contribuir, desde a região, para agilizar os processo de integração. Decidiu, desse modo, o novo governo venezuelano jogar seu peso político, a força de seu mercado e de seu setor produtivo, particularmente o petrolífero, em favor da união da América Latina (CERVO, 2001, p. 163-164, grifo dos autores). 
Isso fica evidente, como exemplo, num discurso de Chávez durante a 30ª Cúpula do Mercosul, em que a Venezuela foi oficializada como membro permanente do bloco. Conforme notícia veiculada no site do Ministério de Comunicação e Informação do Governo Bolivariano da Venezuela, Chávez coloca a importância da efetivação de um mundo "pluripolar", ou seja, sem uma liderança hegemônica, defendendo uma integração social para que seja consolidada a formação de um bloco do Sul: "A América Latina tem o necessário para ser uma potência mundial" (HERRERA, 2006, p. 01), em que Chávez propõe a formação de uma comissão estratégica que organize e planifique os projetos complementares.

Dessa maneira, a revolução bolivariana se constituiu, em boa medida, na resposta do governo Chávez às críticas que ele movia às relações internacionais contemporâneas. As críticas contemplam a autonomia decisória; a desconfiança em face da hegemonia norte-americana; e a necessidade de construir uma unidade latino-americana, para baixar a vulnerabilidade e a dependência vis-à-vis com os Estados Unidos.

A Constituição Bolivariana de 1999 prevê a elaboração de um plano de desenvolvimento nacional a cada seis anos. No primeiro Plano de Desenvolvimento da Nação 2001-2007, a proposta de política externa do governo para o período se apresenta de maneira sistematizada, com estratégias claras de atuação na América Latina, e define como prioridade a construção de um mundo multipolar.

O objetivo enunciado no eixo internacional do Plano da Nação 2001-2007 é o de "fortalecer a soberania nacional e promover um mundo multipolar". Para se chegar a essas duas finalidades, a agenda propõe diversificar "las modalidades de relacionamiento, privilegiando las relaciones con los países latinoamericanos y caribeños y redefiniendo el modelo de seguridad hemisférica" (MPD, 2001, p. 142).

O centro da agenda venezuelana continua sendo a questão energética, mas não necessariamente o petróleo. As duas principais economias sul-americanas têm uma razoável produção de petróleo para o abastecimento do mercado interno e grande potencial de produção de energia hidroelétrica, mas a ausência de investimento no setor durante a neoliberal década de noventa, levou essas economias à dependência do gás natural e da termoeletricidade. A Bolívia, principal e quase exclusivo exportador de gás natural ao Brasil e à Argentina, apresenta dificuldades para investir no aumento de sua produção. A integração energética se coloca, portanto, como o fio propulsor da política chavista para a região (BARROS, HITNER, 2007, p. 07).

Respaldando-se no mandato integracionista da Constituição Bolivariana e argumentando que os grandes problemas latino-americanos como a pobreza e as desigualdades sociais podem ser mais bem abordados na medida em que a integração regional se aprofunde, a proposta de política externa do Plano da Nação busca encetar um conteúdo político ao processo de integração, fomentando o diálogo sul-sul a partir de uma agenda propositiva, articulado foros, debate e atuação em temas como investimento, transferência de tecnologia, dívida pública e biodiversidade (MPD, 2001, p. 147).

Portanto, a Venezuela, no período do governo de Hugo Chávez, tem uma política com um novo viés nacionalista, aumentando as tensões com os EUA. Nas relações internacionais, isso significa a busca do multilateralismo como forma de legitimação interna 
e externa do governo. Essa política multilateralista anti-hegemônica chavista precisa de uma maior integração latino-americana como forma de se firmar no cenário internacional, de modo que o país, a partir de 2001, volta suas forças para a sub-região, procurando um aprofundamento das suas relações com os países vizinhos.

O fato é que, apesar do discurso radical antiamericano de Hugo Chávez, o país continua tendo os EUA como seu principal parceiro comercial, cabendo a este $60 \%$ da produção venezuelana de petróleo, segundo Informe de Gestão de 2008 da Pdvsa. Entretanto, o uso político que Chávez vem fazendo do petróleo é crucial para entender suas relações com a América Latina. Graças às receitas vindas do petróleo, a Venezuela, cuja economia é monoexportadora, mas que prescinde da importação de muito do que consome, pôde negociar sua entrada no Mercosul, que vai passar a ser um bloco de cerca de 250 milhões de habitantes, com grandes expectativas de aumento das exportações, especialmente de produtos industriais para o mercado venezuelano.

\section{Mercosul}

O Mercosul inicia oficialmente com a assinatura do Tratado de Assunção, em 1991, com a participação de Brasil, Argentina, Uruguai e Paraguai, mas surge principalmente da reaproximação entre brasileiros e argentinos, iniciada mais fortemente nos anos 80 , dentro do contexto da redemocratização dos dois países. Pelo tratado, o mercado entraria em funcionamento a partir de 31 de dezembro de 1994, implicando principalmente em:

- Livre circulação de bens, serviços e fatores produtivos entre os países, através, entre outros, da eliminação dos direitos alfandegários e restrições não tarifárias à circulação de mercadorias e de qualquer outra medida de efeito equivalente;

- Estabelecimento de uma tarifa externa comum, a adoção de uma política comercial comum em relação a terceiros Estados e a coordenação de posições em foros econômicos/comerciais regionais e internacionais;

- A coordenação de políticas macroeconômicas e setoriais entre os Estados-Partes de comércio exterior, agrícola, industrial, fiscal, monetária, cambial e de capitais, de serviços, alfandegária, de transportes e comunicações e outras que se acordem, a fim de assegurar condições adequadas de concorrência entre os países-membros;

- E o compromisso dos Estados-Partes de harmonizar suas legislações, nas áreas pertinentes, para lograr o fortalecimento do processo de integração.

Ou seja, a economia é o foco do Mercosul, com o objetivo de tornar os mercados dos quatro países competitivos para concorrer no âmbito internacional e aumentar os superávits na balança comercial, incrementando a verba para investimento em melhorias dos setores produtivos, para gerar mais exportações e, nesse ciclo, mais riqueza para ser investida. Tudo isso dentro do contexto neoliberal da época, em que os governos latino-americanos adotaram o Consenso de Washington ${ }^{(2)}$. E, sob o ponto de vista do comér-

(2) O Consenso de Washington refere-se a uma reunião ocorrida em 1989 entre acadêmicos e economistas estadunidenses, funcionários do governo, do Banco Mundial e do Fundo Monetário Internacional (FMI). Dessa reunião saiu este documento, 
cio, houve um forte avanço entre os países do Mercosul. De acordo com a Conferência das Nações Unidas sobre Comércio e Desenvolvimento (UNCTAD), as exportações do Mercosul por região cresceram de 8,86\% em 1990 para 24,98\% em 1998, ano que evidencia o princípio da queda intra-Mercosul, antes das graves crises econômicas que atingiram a economia mundial no fim da década de $90^{(3)}$.

Outro ponto favorável à integração foram as concessões feitas pelo Brasil para a Argentina no início do bloco. Apesar do avanço no comércio, a Argentina demonstrava insatisfação devido aos déficits comerciais bilaterais com o Brasil nos primeiros anos do bloco. Isso fez com que a Argentina elevasse, ao final de 1992, a taxa de estatística incidente sobre as importações de três para dez por cento, com o consentimento brasileiro, que passou também a importar petróleo e trigo do vizinho, fazendo com que, nos anos seguintes, a balança comercial pendesse quase sempre favorável à Argentina. Além disso, outros fatores corroboraram para esta época, de acordo com Laura Silva (2006), principalmente a existência de interesses iguais entre os Estados, a agenda de integração foi cumprida nos anos iniciais do bloco, os Estados aumentaram sua interdependência por conta do incremento dos fluxos comerciais dentro do Mercosul e a consequente importância desse acréscimo à economia de cada Estado-membro. Esses fatores conjugados marcam este período ${ }^{(4)}$, evidenciando um esforço entre os países para que o processo de integração desse certo.

Já a segunda fase é marcada pelo Protocolo de Ouro Preto, de 17 de dezembro de 1994, quando entra em vigor a União Aduaneira, ainda que de forma incompleta. O Protocolo traz muitas definições quanto à institucionalidade do Mercosul, estabelecendo seus órgãos decisórios, instituindo um órgão de solução de controvérsias e, por fim, o mais importante: somente a partir daqui o Mercosul adquire personalidade jurídica, tornando-se um organismo internacional, entendido como outras pessoas jurídicas de direito internacional público, conforme artigo 34 do capítulo 2 do Protocolo, "estipulando, por seu turno, o artigo 35, 'o Mercosul poderá, no uso de suas atribuições, praticar todos os atos necessários à realização de seus objetivos' (...), enquanto que o artigo 36 prevê 'o Mercosul celebrará acordos de sede"' (CASELLA, 1996, p. 269).

O Protocolo de Ouro Preto trouxe algumas definições no âmbito da institucionalidade do Mercosul, mantendo a grande maioria de seus órgãos de forma permanente. No entanto, sob o ponto de vista econômico, não ocorreu um aprofundamento da integração, apesar de o comércio continuar avançando no período entre 1995 e 1998. Por exemplo, não houve um acordo sobre a remoção de barreiras não tarifárias, nem sobre a questão macroeconômica e a própria definição da Tarifa Externa Comum foi um árduo trabalho. E isso pode ter ocorrido por uma possibilidade:

"Durante este período, a imagem prevalecente era a de que o Mercosul era tão bem-sucedido que poderia progredir impulsionado tão somente pelos interesses do setor privado,

criado pelo economista John Williamson, que recomendava, entre outras coisas: disciplina fiscal, taxas de juros positivas e determinadas pelo mercado, câmbio competitivo, abertura ao investimento estrangeiro, liberalização do comércio, permitindo mais facilidades à entrada de produtos estrangeiros, privatização de empresas estatais, desregulamentação do sistema financeiro.

(3) Após a crise mexicana em 1994, um efeito cascata de crises econômicas atingiu outros emergentes: Ásia em 1997, Rússia em 1998 e o próprio Brasil em 1999.

(4) É o que a autora define como "período de transição", ou seja, a primeira fase do Mercosul, que vai de 1991 a 1994. 
enquanto a agenda política ficava relegada a segundo plano. Como os eventos demonstram mais tarde, o Mercosul começou a acumular uma crescente quantidade de negócios pendentes" (BOUZA apud SILVA, Laura, 2006, p. 80).

Dali em diante, o Brasil começou a relutar em ceder às pressões argentinas em prol da continuidade da integração, mesmo ainda considerando o Mercosul importante na política externa brasileira. Para piorar, a partir de $1999^{(5)}$ o fluxo de comércio intrarregional começou a sofrer um revés e tornou-se menos dinâmico, fazendo com que a falta de acordos aumentassem as pendências e, consequentemente, as divergências entre Brasil e Argentina se multiplicassem. Outro fator que marca o início desse processo é a desvalorização da moeda brasileira em 1999, sem consulta prévia aos parceiros do bloco, que proporcionou a desvalorização do câmbio, influenciando negativamente nos preços dos produtos e na balança de pagamentos dos países. A atividade econômica e o comércio intrabloco arrefeceram, provocando medidas protecionistas, principalmente da Argentina, com medo de diminuir suas exportações para o Brasil e ver seu país inundado de produtos brasileiros. Conforme Laura Silva (2006), de 35,64\% das exportações destinadas ao Mercosul pela Argentina em 1998, esse total chegou apenas a 19,59\% em 2004. Do lado brasileiro, de $17,37 \%$ em 1998, o percentual de exportações para o bloco caiu para 9,24\% em 2004.

Apesar de o Mercosul ter proporcionado um incremento comercial durante seus primeiros anos, aumentando a interdependência entre os sócios, não foi suficiente para confirmar o comprometimento dos países no bloco, submetendo seus interesses particulares aos benefícios do bloco (SILVA, 2006). Já nos anos 2000, a entrada de governantes com raízes sociais mais populares, mais preocupados com o crescimento econômico e com o desenvolvimento social ${ }^{(6)}$ e um ambiente internacional favorável, auxiliam a colocar o Mercosul de volta à pauta regional como um projeto mais atuante e estratégico. É dentro desse contexto, de boas intenções, mas de práticas econômicas entravadas dentro do bloco, que a Venezuela procura o Mercosul com o objetivo de ser um membro pleno.

\section{A entrada da Venezuela no Mercosul}

A Venezuela saiu em abril de 2006 da Comunidade Andina de Nações e entrou oficialmente como membro pleno do Mercosul em 4 de julho daquele ano, fazendo com que o bloco passasse a ter mais de 250 milhões de habitantes, uma área de 12,7 milhões de $\mathrm{km}^{2}$, um PIB superior a US\$ 1 trilhão e um comércio global superior a US\$ 300 bilhões (BACOCCINA, 2006, p, 03). O Protocolo de Adesão, assinado em Caracas,

(5) Quando marca o período de crise do bloco, entre 1999-2004, segundo a autora já citada.

(6) Apesar de chamados pela mídia de "esquerdistas", nem sempre isso corresponde ao real sentido da palavra, que muito pouco significado tem nos dias de hoje. De qualquer forma, é dever perceber nos últimos anos a ascensão de presidentes com base social mais popular, possuindo, consequentemente, mais preocupações sociais. São eles: Hugo Chávez (Venezuela, 1999), Luis Inácio Lula da Silva (Brasil, 2003), Tabaré Vázquez (Uruguai, 2005), Evo Morales (Bolívia, 2006), Daniel Ortega (Nicarágua, 2006) Cristina Kirchner (Argentina, 2007), Rafael Correa (Equador, 2007), Fernando Lugo (Paraguai, 2008) e Mauricio Funes (El Salvador, 2009). 
estabelece como prazo quatro anos para a Venezuela se adaptar às principais regras aduaneiras do bloco, como a adoção da Tarifa Externa Comum e todo o acervo normativo. Além disso, a partir de 2010, Brasil e Argentina não mais cobrarão tarifas de importação dos produtos venezuelanos, exceto uma lista de mercadorias sensíveis. Em 2012, é a vez de as exportações brasileiras e argentinas, também exceto produtos sensíveis, entrarem com tarifa zero na Venezuela. Já Paraguai e Uruguai foram beneficiados com tarifa zero desde a assinatura do protocolo. Sob o ponto de vista do bloco, a entrada da Venezuela no Mercosul é importante por ter um novo mercado para receber seus produtos. Tanto que as exportações brasileiras entre 2004 e 2005 já haviam crescido 51,3\%, enquanto que no caso argentino a elevação foi de 17,9\% (MARREIRO, 2006, p, 01).

No entanto, para que o Protocolo seja colocado em prática, é preciso que os parlamentos dos países-membros ratifiquem-no, o que continua pendente nos Poderes Legislativos de Brasil e Paraguai. Aprovado pela Câmara dos Deputados, a entrada da Venezuela prossegue pendente no Senado brasileiro, sob amplo debate.

Apesar desse entrave, a Venezuela já faz parte do Mercosul como membro pleno desde a assinatura do Protocolo, como esclarece o artigo oitavo, estabelecendo uma categoria não prevista no Tratado de Assunção, que prevê primeiro a adequação do país às normas do Mercosul para depois fazer parte do mesmo. Ou seja, o novo membro já integra a delegação nas negociações com os países fora do bloco. Uma explicação possível para isto pode estar no próprio texto do Protocolo, que afirma "a importância da adesão da República Bolivariana da Venezuela ao Mercosul para a consolidação do processo de integração da América do Sul no contexto da integração latino-americana" (MERCOSUL, 2006, p. 01). O discurso de Lula na cerimônia de assinatura do Protocolo vai pelo mesmo caminho:

"A adesão da Venezuela ao Tratado de Assunção é mais do que um voto de confiança na força de nosso projeto comum. A expansão de nosso bloco até o Caribe reforçará a percepção de que o Mercosul é uma realidade continental e ajudará a visualizar o Mercosul como a espinha dorsal da integração da América do Sul" (SILVA, Luiz, 2006, p. 01).

Sob o ponto de vista brasileiro, a perspectiva é tanto econômica quanto estratégica. Como já citado, um novo mercado importador surge para os produtos brasileiros, bem como a possibilidade de uma integração energética com um parceiro que é o quarto maior produtor de petróleo do mundo e dono de uma parte importante da Amazônia. Sob o âmbito estratégico, é a visão de um parceiro de pujança no contexto sul-americano, como afirmou à época para a Folha de S. Paulo o embaixador José Antonio Marcondes, chefe do Departamento de Integração do Itamaraty: a Venezuela é um país politicamente importante na América do Sul. O Mercosul deixa de ter um contexto de Cone Sul para ter um contexto regional, do Caribe à Patagônia (BACOCCINA, 2006, p, 01). Ou seja, dá uma amplitude maior para o bloco, no sentido de ganhar uma notoriedade em toda a América do Sul, não mais se restringindo ao Cone Sul.

Mas qual seria o interesse da Venezuela em adentrar ao Mercosul? Político? Econômico? Estratégico? Retórico? São essas interrogantes que propomos refletir a seguir. 


\section{Por Que o Mercosul?}

Sob o ponto de vista venezuelano, a entrada do país no Mercosul pode ser analisada sob dois aspectos. O primeiro deles é a possibilidade de abrir um mercado importante para a aquisição de produtos dos atores do bloco, com tarifas reduzidas, suprindo parte significativa de suas necessidades, já que o parque industrial da Venezuela está direcionado, majoritariamente, ao petróleo e seus correlatos. Mas o mesmo vale no sentido inverso: são novos países compradores de seu petróleo, numa tentativa de diminuir a dependência em relação aos Estados Unidos. Isto pode nos fazer acreditar que os esporádicos ataques de Chávez ao Mercosul se dariam muito mais quanto ao projeto político do bloco, querendo forjar um novo, enquanto deseja aproveitar as benesses econômicas do processo de integração.

O segundo aspecto é estratégico: a atuação da Venezuela no Mercosul aproxima Caracas a Brasília e Buenos Aires, os dois pilares do Mercosul, como vimos acima, sendo, por isso, prioritária essa aproximação com o bloco. E principalmente no que se refere ao Brasil, verdadeira menina dos olhos dos investidores internacionais e dos presidentes do mundo todo, a aproximação de Chávez a Lula busca uma legitimidade às ações venezuelana dentro de um contexto maior de integração latino-americana, totalmente condizente, neste sentido, com a política externa brasileira de integrar o subcontinente.

Apesar de Chávez ganhar ascendência na América Latina, após a acomodação de Lula com os EUA e o sistema financeiro internacional, a Venezuela depende do Brasil para pôr em marcha qualquer projeto de integração que reúna todo o subcontinente (CARMO, 2007, p. 38). Apesar do discurso radical, Chávez faz sempre concessões para que o Brasil esteja junto às negociações relacionadas à integração que a Venezuela faça parte. Do outro lado, Lula, por sua base social e sua origem, evita atritos com as iniciativas chavistas, mas acaba por impor um ritmo mais lento. O discurso não é agressivo, tomando, enfim, uma postura pragmática.

Essa integração sem volta tem a energia como método, sendo a Alba e a Petroamérica o ponto de partida para o aprofundamento desse processo integracionista no subcontinente:

Os eixos principais dessa estratégia são, em primeiro lugar, a ideia de uma liderança venezuelana com a finalidade de fomentar a integração bolivariana. Em segundo lugar, como vimos anteriormente, a constituição de um 'eixo Sul' junto com o Brasil e a Argentina, como primeiro passo para a constituição de um mundo multipolar. Por último, uma reformulação do Mercosul para privilegiar o tema dos chamados 'déficits sociais', bem como atribuir maior importância aos conteúdos políticos. Do ponto de vista venezuelano, os temas comerciais e econômicos passariam a ter um papel secundário (JÁCOME, 2007, p. 82).

Cabe ainda ponderar a respeito de um terceiro item, relacionado à integração, mas de fundo mais interno. Os projetos de integração apresentados pela Venezuela são sempre de caráter político, ou seja, motivados por razões de poder, com o objetivo de aumentar o poder dos Estados do subcontinente, diminuindo sua dependência, além de frear a dominação política e econômica dos EUA na região (CARMO, 2007, p. 30). A integração 
que Chávez busca tem como objetivo impedir um caminho inverso após sua saída, por isso: "Chávez insiste numa integração com uma concepção política claramente definida; busca uma integração sul-americana bolivariana (ainda que fora da Alba) para que sirva de barreira a eventuais políticas bolivarianas no interior da Venezuela" (CARMO, 2007, p. 35).

Pelo que foi exposto acima, o Mercosul se mostra importante para a Venezuela, inicialmente, na questão das relações econômicas, em que pese o surgimento de parceiros vizinhos para incrementar as exportações e importações para o país, num princípio de desvinculação da Venezuela quanto a um mercado prioritariamente exportador de petróleo para os Estados Unidos, que a torna vulnerável, também, sob o ponto de vista político. E aí reside o segundo ponto de vista mencionado anteriormente: uma integração subcontinental, que parte dos recursos naturais energéticos para não haver retorno, é vital para a consolidação do projeto bolivariano, tanto internamente quanto na América Latina, tendo a Argentina, mas, principalmente, o Brasil, como um ator vital para a continuação do andamento dos processos de integração no subcontinente, mesmo que não partilhando do teor bolivariano incrustado na retórica chavista.

\section{Alba: um Projeto político}

A Alternativa Bolivariana das Américas (Alba) é um projeto central na atual política exterior da Venezuela. Proposta oficialmente por Chávez no III Encontro de Chefes de Estado e Governo da Associação dos Estados do Caribe, ocorrida na ilha de Margarita, na Venezuela, em dezembro de 2001, ela teve seu embrionário durante o já citado Paro Petrolero, quando, durante um período de incertezas e de polarização social no país, Cuba estendeu a mão com o envio de técnicos da área de petróleo, entre outros tipos de ajuda, evidenciando o papel que poderia ter a Alba no sentido de atuar como uma forma de auxílio a governos próximos ideologicamente.

Esse evento, portanto, consolidou a aliança necessária para construir a Alba, culminando na "Declaración Conjunta" e no "Acuerdo entre el Presidente de La República Bolivariana de Venezuela y el Presidente del Consejo de Estado de Cuba, para la aplicación de la Alternativa Bolivariana Para Las Américas", primeiros documentos oficiais da Alba, assinados em 14 de dezembro de 2004. Enquanto o segundo sela vários acordos entre os dois países, o primeiro parte para os princípios que devem reger a Alba, entre outras coisas, promovendo a solidariedade e a cooperação entre os dois povos. E ataca a visão oposta disto:

El ALBA no se hará realidad con criterios mercantilistas ni intereses egoístas de ganancia empresarial o beneficio nacional en perjuicio de otros pueblos. Sólo una amplia visión latinoamericanista, que reconozca la imposibilidad de que nuestros países se desarrollen y sean verdaderamente independientes de forma aislada (...) para diferenciarla de la otra América, expansionista y de apetitos imperiales (ALBA, 2004, p. 01).

A Alba, criada em oposição a Área de Livre-Comércio das Américas (Alca), surge para denunciar o conservadorismo e o neoliberalismo imposto pelos Estados Unidos. 
A proposta de fortalecimento do processo de integração sul-americano, baseado no modelo da Alba, está de acordo com a Constituição Bolivariana, aprovada em 1999, que aponta em seu artigo 153: "La República promoverá y favorecerá la integración latinoamericana y caribeña, en aras de avanzar hacia la creación de una comunidad de naciones, defendiendo los intereses económicos, sociales, culturales, políticos y ambientales de la región" (CONSTITUIÇÃO DA REPÚBLICA BOLIVARIANA DA VENEZUELA, 1999, p. 36). Outro documento importante que indica as diretrizes da política externa do governo Chávez é o Plan de Desarollo 2001-2007. Em seu item 5.2 Promover la integración latinoamericana y caribeña, é evidente o cunho social e político que a Venezuela dá a seus projetos de integração:

"[...] la cohesión de los países latinoamericanos y caribeños, mediante la consolidación e instrumentación de su identidad común, se convertirá en el mecanismo idóneo para ampliar las oportunidades de crecimiento y desarollo de la región y mejorar en forma sostenida y equitativa sus niveles de bienestar social" (MPD, 2001, p. 143).

Portanto, os projetos de integração apresentados pela Venezuela possuem caráter prioritariamente político, sendo motivados por razões de poder, neste caso, aumentando o poder dos Estados do subcontinente e, consequentemente, diminuindo sua dependência, além de frear a dominação política e econômica dos EUA na região.

\section{QUASE CINCO ANOS}

Já são quase cinco anos desde a assinatura da "Declaración Conjunta", em que Cuba e Venezuela firmaram acordos nas áreas de educação, saúde, energia, comércios, financiamentos, entre outros, visando a cooperação mútua e a solidariedade, basilares dentro do ponto de vista da Alba. Com a entrada posterior de Bolívia, Nicarágua e, mais recentemente, Dominica e Honduras, os acordos podem ser ampliados e aprofundados.

Mas uma das centralidades nos acordos propostos pela Venezuela está a integração energética, como pontapé para a integração propriamente dita. E o primeiro passo concreto nesse sentido foi o "Acuerdo de Cooperación Energética Petrocaribe", de 29 de junho de 2005. Dentro deste acordo está, além da criação da Petrocaribe, o fundo "Alba-Caribe", para investimentos para o desenvolvimento econômico social da região. O curioso é ir ao final do documento e ver a lista de países que assinaram o acordo: Antígua e Barbuda, Bahamas, Belize, Cuba, Dominica, República Dominicana, Granada, Guiana, Jamaica, São Vicente e Granadinas, Santa Lúcia, São Cristóvão e Neves, Suriname e Venezuela. Ou seja, vários países da América Central, do Sul e, principalmente, Caribe participam do acordo para a criação de empresas, mas não aderem, necessariamente, à Alba, legitimando-a, porém, por conta da dependência ao petróleo e do financiamento que a verba relacionada ao projeto pode ser usada para outros investimentos, caso da "Alba-Caribe" (CARMO, 2007, p. 37).

Ainda na questão energética, em 29 de abril de 2007, durante o II Encontro da Alba, os então quatro governos pertencentes à Alba (Bolívia, Cuba, Nicarágua e Venezuela) firmaram o "Tratado Energético del Alba". Dos principais pontos a destacar está a 
exclusividade à Alba de uma faixa petrolífera do rio Orinoco na Venezuela, para garantir o abastecimento dos países pelos próximos 25 anos, a ser operada pela empresa "Gran Nacional" Petroalba. Ainda dentro deste tratado está a criação de refinarias em Bolívia, Nicarágua e Cuba, sem falar que nesta última já existe, há quatro anos, a Pdvsa Cuba, que reativou a refinaria Camilo Cien-fuegos. A diretora executiva do Instituto Venezuelano de Estudos Sociais e Políticos (INVESP), Francine Jácome, aprofunda como a questão energética é prioritária no processo de integração e vai além de uma petrolífera caribenha. Para ela, o surgimento da Petroamérica se daria dentro da Alba, fazendo com que a integração energética seja possível após diversos acordos entre as diversas estatais petroleiras da região: "Em função disso, já foram propostas três iniciativas sub-regionais, a saber: Petrosul (Argentina, Brasil, Uruguai e Venezuela), Petrocaribe (14 países do Caribe) e Petroandina (Bolívia, Colômbia, Equador, Peru e Venezuela)" (JÁCOME, 2007, p. 85).

Outro projeto elaborado é o Tratado de Comércio entre os Povos (TCP), assinado em 29 de abril de 2006 pela Bolívia, Cuba e Venezuela, que, como explica o "Comunicado Conjunto", da mesma data, serve como "instrumentos de intercambio solidario y complementario entre los países destinados a beneficiar a los pueblos en contraposición a los Tratados de Libre Comercio que persiguen incrementar el poder y el dominio de las transnacionales" (ALBA, 2006, p. 01). Nele, estão previstos vários tipos de ações entre os três países, cada um utilizando seu forte para ajudar numa área em que o outro possui debilidades. Como exemplo, a criação de uma empresa "Gran Nacional" para fomentar indústrias nos países da Alba; criação de uma empresa de importação e exportação; rede de armazenamento e comercialização de bens; Feira Internacional da Alba; criação de um centro de formação para a pesquisa e inovação tecnológica, assistência técnica e formação para melhorar a capacidade e qualidade produtiva.

Já dentro do contexto de crise internacional atual, durante o Quinto Encontro extraordinário Alba - TCP, ocorrido em 16 e 17 de abril deste ano, a declaração final do encontro ressalta, entre outras coisas, a necessidade de estabelecer uma nova ordem econômica internacional, que tenha entre seus princípios fundamentais a justiça e a solidariedade. Além disso:

[...] reiteraron su voluntad en unir esfuerzos para la construcción de un sistema monetario y financiero sólido y justo, regido por mecanismos de toma de decisiones transparentes y abiertos, que privilegien la participación de todos los Estados en condiciones de igualdad, independiente de los patrones neoliberales y del modelo internacional prevaleciente desde el fin de la Segunda Guerra Mundial, cuya propia naturaleza es co-responsable de los actuales desajustes (ALBA, 2009, p. 02).

Outro elemento importante de ser citado é a criação do Banco da Alba, por meio de um memorando assinado por Bolívia, Cuba, Nicarágua e Venezuela, em 6 de junho de 2007, com o objetivo de aumentar os investimentos, ampliando os programas de cooperação e dos projetos de desenvolvimento produtivo, como diz o texto do documento. Em funcionamento desde 2008, o banco servirá como um incentivador dos projetos dentro do âmbito da Alba, pois, como declarou Chávez à Telesur: "não existe desenvolvimento 
econômico se não aumentarmos a capacidade de capital e, sobretudo, de investimento (BANCO ALBA..., 2008, p, 01). Esse enfoque comercial-econômico culmina na criação do Sistema Único de Compensação Regional (Sucre), uma unidade monetária virtual para a troca comercial em substituição ao dólar, que se pretende que tenha circularidade física no futuro. Seu objetivo é o de construir uma zona monetária unida e um fundo de reservas, com participação dos países-membros, para sustentar as políticas de desenvolvimento em curso.

\section{Alba e Venezuela}

A vitória de Chávez no referendo revocatório em agosto de 2004 abriu espaço definitivo para uma atuação mais incisiva de seu governo nas relações internacionais, já que no plano interno, sua supremacia estava legitimada por alguns anos. Jácome (2007) estabelece essa fase como uma nova etapa na política externa, que busca consolidar a revolução bolivariana, declarada socialista, também no plano internacional, principalmente a partir da metade de 2005:

Isso significou um aumento na beligerância, pelo menos no discurso, contra os Estados Unidos; o aprofundamento dos vínculos com Cuba e outros países como Irã, Rússia, China, Coreia do Norte e Líbia; a busca de influência em processos internos dos países da região, como mostraram os casos recentes de Bolívia, Equador e Nicarágua; bem como um processo que busca reforçar a liderança presidencial, não somente no âmbito regional, mas mundial (JÁCOME, 2007, p. 68).

No plano da América Latina, por sua vez, é a consolidação de um projeto que vem, desde a Constituição Bolivariana de 1999, mudando o enfoque de atuação da Venezuela, de um país voltado para os Estados Unidos para um ator firme no subcontinente, ao mesmo tempo em que rompe - mais no discurso do que no comércio, ainda que com lentas mudanças - com o gigante do Norte. O objetivo agora é unir os vizinhos mais pobres da América numa rede de proteção contra as investidas dos países já desenvolvidos, dando um caráter mais político aos processos de integração que Chávez procura pôr em curso. "Venezuela concebe um processo de integração em bases não só econômicas, mas também profundamente políticas. Também concebe o processo de integração como um processo anticapitalista, coerente com sua visão do 'socialismo do século XXI'" (VILLA, 2007, p. 42).

Diante disso, a Alba procura cumprir um primeiro papel que é fortalecer os países do Caribe e da América Central — histórica área de influência estadunidense -, sempre fragilizados devido a seu tamanho e sua pobreza. Por isso, a Alba está assentada em quatro elementos: complementaridade, cooperação, solidariedade e respeito pela soberania dos países. Um documento chamado "¿Qué es el Alba?", do próprio site da entidade, evidencia esse caráter político, social e, até mesmo, ideológico:

Mientras el ALCA responde a los intereses del capital trasnacional y persigue la liberalización absoluta del comercio de bienes y servicios e inversiones, el ALBA pone el énfasis en 
la lucha contra la pobreza y la exclusión social y, por lo tanto, expresa los intereses de los pueblos latinoamericanos. El ALBA se fundamenta en la creación de mecanismos para crear ventajas cooperativas entre las naciones que permitan compensar las asimetrías existentes entre los países del hemisferio (BOSSI, s/d, p. 01).

Por tudo isso, e dentro da perspectiva chavista, é vital que a Alba continue atraindo os presidentes do Caribe, da América Central e da América do Sul, para que tornem a Venezuela forte externamente, diminuindo sua vulnerabilidade quanto a um possível ataque dos Estados Unidos.

\section{CONCLUSÃO}

A polarização política na Venezuela e as mudanças institucionais puseram fim aos quarenta anos de Punto Fijo e instauraram um novo período na política venezuelana intimamente ligado à figura de Hugo Chávez, que rompe com a "Doutrina Betancourt" e organiza as mudanças institucionais de modo a mesclar a política de Estado com a política de governo. Isso aconteceu em todos os âmbitos da política, incluindo a política externa, que é um importante instrumento da "revolução bolivariana".

A Venezuela é um país atípico na América Latina porque tem no petróleo sua principal fonte de renda, o que fez com que sua política externa tenha sido voltada quase sempre para fora do subcontinente. Quando Chávez assume o governo, apesar da pouca mudança ocorrida nas suas relações com seu maior crítico e parceiro econômico, o discurso do governo venezuelano aponta na direção de um questionamento do modelo unilateral e hegemônico dos EUA, e da busca de um modelo mais multilateral.

Essa posição, que se mostra cada vez característica do governo venezuelano, só se torna possível devido à conjuntura internacional favorável e devido, sobretudo, à alta dos preços do petróleo. A região sul da América Latina, principalmente Brasil e Argentina, vivem conjuntura também favorável ao chavismo, principalmente depois da eleição de Lula e Nestor Kirchner, que se apresentaram como aliados ao governo de Chávez e se colocaram de forma crítica em relação à política hegemônica norte-americana.

Portanto, se num primeiro momento as preocupações externas do governo chavista foram dirigidas à rearticulação da Opep, a partir de 2001 é nítida a mudança de prioridade em direção à integração sul-americana, sobretudo em sua forma. Por um lado, Chávez propõe a Alba como alternativa à Alca. Ao contrário de uma integração comercial, a Alba seria um tipo de integração política, de apoio mútuo entre os países "bolivarianos" da América Latina. Essa proposta sensibilizou de imediato apenas Cuba e, um pouco depois, a Bolívia, com a chegada de Evo Morales ao governo, mas sensibilizou muito pouco os outros países da América do Sul. A Alba serve como importante instrumento de política externa para a Venezuela, pois amplia sua área de influência no Caribe e América Central, dando mais autonomia aos países da região, ou tentando protegê-los das investidas dos EUA.

Diante desse cenário, a entrada da Venezuela no Mercosul foi uma escolha política quase necessária, uma vez que o Mercosul é importante para o país aumentar o número 
de parceiros comerciais da Venezuela, além de fortalecê-la na região. No Plano de Desenvolvimento da Nação (2001-2007), o objetivo da política externa chavista era investir no fortalecimento da CAN para que os países-membros do bloco se aproximassem, em conjunto, ao Mercosul. Entretanto, após a promulgação dos Tratados Bilaterais de Livre-Comércio com Estados Unidos pela Colômbia, Peru e Equador, essa alternativa tornou-se inviável, ocasionando a saída da Venezuela desse bloco e a subsequente entrada no Mercosul.

Portanto, como se vê, as políticas integracionistas se colocam de forma vital para a perspectiva chavista de manter seu projeto "bolivariano" vivo internamente, já que conta com o apoio dos vizinhos que possuem preocupação social e ligações populares semelhantes e veem com bons olhos um governo que esteja disposto a investir em projetos de desenvolvimento econômico e social para o subcontinente. Mas a busca por integração também permite à Venezuela almejar uma projeção na política externa, ao aumentar sua influência na região, além de obter novos parceiros comerciais que possam auxiliar o país a transformar sua cultura monoexportadora com base no petróleo para uma produção mais diversificada, reduzindo, também e com isso, a dependência a seu principal adversário no campo retórico e ideológico, colocando, assim, em prática, o que se conhece de cor e salteado no discurso chavista.

\section{Bibliografia}

ALBA. Acuerdo de Cooperación Energética Petrocaribe. Puerto La Cruz, 2005.

. Acuerdo entre el Presidente de La República Bolivariana de Venezuelay el Presidente del Consejo de Estado de Cuba, para la aplicación de la Alternativa Bolivariana Para Las Américas. Havana: 2004. . Comunicado conjunto. Havana, 2006.

. Declaración Conjunta. Havana, 2004.

. Quinto Encontro Extraordinário Alba - TCP. Cumaná, 2009.

Tratado energético del Alba. Barquisimeto, 2007.

BACOCCINA, Denize. Venezuela entra no Mercosul para reforçar integração. BBC Brasil. Brasília, p. 3, 04 jul. 2006. Disponível em: <http://www.bbc.co.uk/portuguese/reporterbbc/story/2006/07/060703_ venezuelamercosull.shtml>. Acesso em: 15 maio 2009.

BANCO ALBA busca combater a dependência financeira junto às IFIs. Adital. Fortaleza: p. 01, 17 jan. 2008. Disponível em: <http://www.adital.org.br/site/noticia.asp?lang=PT\&cod=31305> . Acesso em: 15 maio 2009.

BARROS, Pedro Silva. Governo Chávez e desenvolvimento: a política econômica em processo. São Paulo, 2007. 161 f. Dissertação (Mestrado em Economia) — Pontifícia Universidade Católica de São Paulo.

; HITNER, Verena. Da CAN ao Mercosul: uma análise da nova política externa venezuelana. Revista da Sociedade Brasileira de Economia Política, v. 20, p. 25-44, 2007.

BOSSI, Fernando R. ¿Qué es el Alba? ALBA. s/d. Disponível em: <http://www.alternativabolivariana. org/modules.php? name=Content $\&$ pa=showpage $\&$ pid=1>. Acesso em: 20 maio 2009.

CARMO, Corival Alves. Confrontando o subdesenvolvimento e a dependência: a Venezuela de Hugo Chávez. In: CARMO, Corival Alves; BARROS, Pedro Silva; MONTEIRO, Leonardo Valente. Prêmio América do Sul - 2007 Venezuela: mudanças e perspectivas. Brasília: FUNAG, 2007. 
CASELLA, Paulo Borba. Mercosul: exigências e perspectivas — integração e consolidação de espaço econômico (1995-2001-2005). São Paulo: LTr, 1996.

CEPAL. El regionalismo abierto em América Latina y el Caribe: la integración económica al servicio de la transformación productiva con equidad. Textos Seleccionados, Cincuenta Años de Pensamiento en la CEPAL, Santiago, CEPAL, v. 2, 1998.

CERVO, Amado Luis. A política exterior da Venezuela. In: ARAÚJO, Heloísa Vilhena. Os países da comunidade andina. Volume 1. Brasília: FUNAG e IPRI, 2004.

A Venezuela e seus vizinhos. Brasília: UNB, 2001.

CONSTITUIÇÃO DA REPÚBLICA BOLIVARIANA DA VENEZUELA: promulgada em 30 de dezembro de 1999. Disponível em: <http://www.constitucion.ve/documentos/ConstitucionRBV1999-ES. pdf>. Acesso em: 4 maio 2009.

HERRERA, Laura Carolina. El objetivo es conformar um mundo pluripolar. Ministério de Comunicação e Informação do Governo Bolivariano da Venezuela. Caracas, 21 jul. 2006. Disponível em: <http:// www.mci.gob.ve/noticiasnuev.asp?numn=10632>. Acesso em: 10 maio 2008.

JÁCOME, Francine. Segurança e integração "bolivariana" no marco da política exterior da Venezuela (1999-2006). Cadernos Adenauer VIII, Rio de Janeiro, Fundação Konrad Adenauer, União Europeia e Mercosul: dois momentos especiais da integração regional, n. 1, maio 2007.

LANDER, Luis E. La reforma petrolera del gobierno Chávez. Revista Venezolana de Economía e y Ciencias Sociales, Caracas, Facultad de Ciencias Económicas y Sociales, Universidad Central de Venezuela, v. 8, n. 2, mayo/ago. 2002.

MARREIRO, Flávia. Venezuela entra hoje no Mercosul. Folha On Line. São Paulo, p. 01, 4 jul. 2006. Disponível em: <http://wwwl.folha.uol.com.br/folha/dinheiro/ult9lu109108.shtml>. Acesso em: 15 maio 2009.

MERCOSUL. Protocolo de Adesão da República Bolivariana da Venezuela ao Mercosul. Caracas: 2006. Protocolo de Ouro Preto. Ouro Preto: 1994.

Tratado de Assunção. Assunção: 1991.

MINISTERIO DE PLANIFICACIÓN Y DESARROLLO. Plan Nacional de Desarrollo Económico y Social de la Nación 2001-2007. Caracas: MPD, 2001.

MOMMER, Bernard. Petróleo global y estado nacional. Caracas: Comala.com, 2003.

PETRÓLEOS DE VENEZUELA S/A. Informe de Gestión Anual 2008. Caracas: PDVSA, 2008.

ROMERO, M. Tereza. Política exterior venezolana. El proyecto democrático 1958-1998. Caracas: Los libros de El Nacional, 2002.

SILVA, Laura. Política externa brasileira para o Mercosul: interesses estratégicos e crise da integração regional. São Paulo, 2006. 107 f. Dissertação (Mestrado em Ciência Política) — Faculdade de Filosofia, Letras e Ciências Humanas, Universidade de São Paulo.

SILVA, Luiz. Discurso do Presidente da República, Luiz Inácio Lula da Silva, na cerimônia de assinatura do Protocolo de Adesão da Venezuela como Membro-Pleno do MERCOSUL. Caracas: 2006. Disponível em: <http://www.mre.gov.br/portugues/politica_externa/discursos/discurso_detalhe3. asp?ID_DISCURSO=2869. Acesso em: 6 maio 2009.

VENEZUELA (Constituição de 1999). Constituição da República Bolivariana da Venezuela: promulgada em 30 de dezembro de 1999. Disponível em: <http://www.constitucion.ve/documentos/ ConstitucionRBV1999-ES.pdf>. Acesso em: 4 maio 2009.

VILLA, Rafael Duarte. Limites do ativismo venezuelano para a América do Sul. Revista de Política Externa, São Paulo, v. 16, 2007.

Venezuela: mudanças políticas na era Chávez. Scielo Brasil, 2005. 
